\title{
Particle dry deposition algorithms in CMAQ version 5.3: characterization of critical parameters and land use dependence using DepoBoxTool version 1.0: Supplement
}

Qian Shu et al.

5 Correspondence to: Qian Shu (shumarkq@gmail.com)

\section{Supplemental Material}

In Fig. S1, to quantify the influence of Stokes number $(S t)$ and impaction $\left(E_{I M}\right)$ formulations on dry deposition velocities, a comparison of the combination of $S t$ and $E_{I M}$ have been tested on the deciduous forest surface category. Observed parameters and $V_{d}$ are from Matsuda et al. (2010). In order to pair with measured study, modeled $V_{d}$ of all

10 combinations are calculated using single diameter as the same as the measurement study $\left(d_{p}=2.5 \mu m\right)$. Detailed formulations are presented in Table S1. From these comparisons, the variation in deposition velocity due to the formulation of the impaction factor exceeds that of the Stokes number formulation.

The daily variations of assumed $w_{\star}$ for three measurement studies discussed in section (2.2.2) were unavailable and thus we approximated them using data from the WRF meteorological model above corresponding land-use types. The

15 approximate $w_{\star}$ for grass and forest surfaces are presented in Fig. S2. Deciduous and coniferous forests are considered to have the same $w_{\star}$ from the forest. All $w_{\star}$ acquired from WRF outputs are UTC-based and were converted to the local time at the locations where measurement studies were conducted.

The sensitivity of bin size in the sectional model on three land-use surface categories is presented in Fig. S3. We used the PR11 scheme to test the influence of bin size on numerical diffusion by comparing different particle numbers from

2010 to 10000. Particle volumes were converted from particle numbers using Eq. (26) based on given particle numbers. When we configure the box model with 10 size bins, the numerical artifact is large in the sectional model, particularly over the deciduous forest case where the 10 size bin case overestimates the more detailed models by a factor of 3 . When we assume large numbers of bins (at least 100) in the sectional model, the predictions converge.

Daily variations of dry deposition velocities calculated for single-diameter particle populations over three land-use

25 surface categories have been presented in Fig. S4. For the grass and deciduous forest cases, we see that the PR11 and VGLAI schemes are better able to capture the diurnal variation in deposition velocity observed, while the Z01 scheme predicts relatively uniform trend throughout the day. For the coniferous forest case, the observations do not suggest an afternoon peak as in the other cases, and all of the schemes appear able to roughly capture the deposition magnitude. The PR11 scheme underpredicts this coniferous forest case by about a factor of 3-8 depending on the time of day, and the VGLAI case performs much better, although slightly overpredicting, by less than a factor of 2 . 
Table S1. Stokes number $(S t)$ and impaction $\left(E_{I M}\right)$ formulations of different studies.

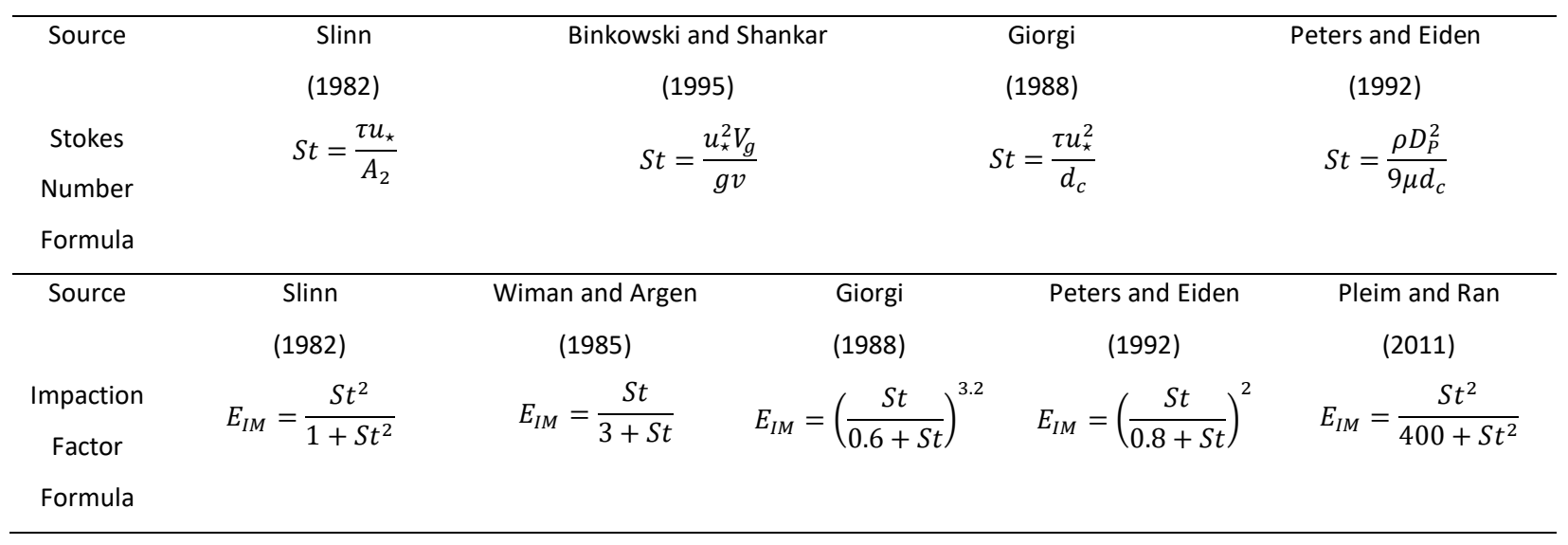




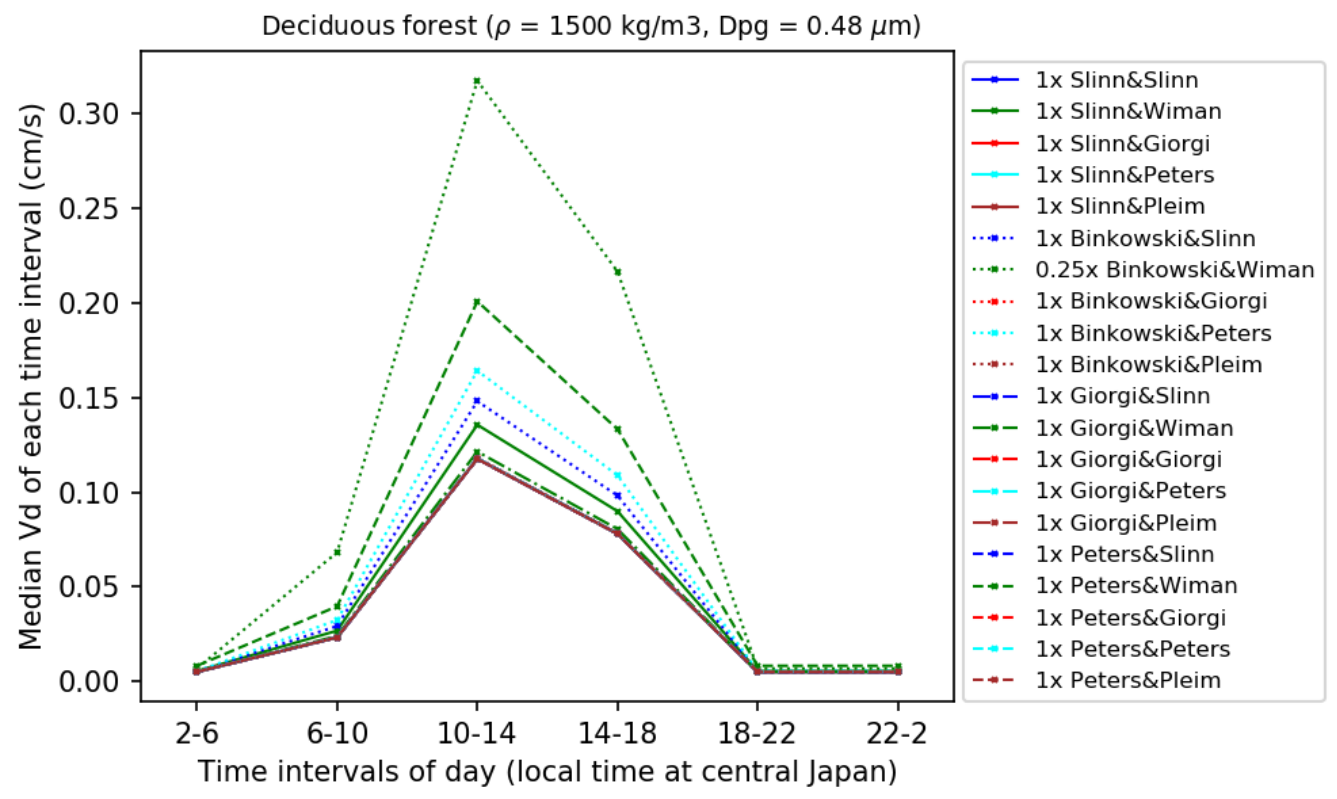

Fig. S1. Diurnal variations of median $\mathrm{V}_{\mathrm{d}}$ on the deciduous forest for different combinations of $S t$ and $E_{I M}$. 


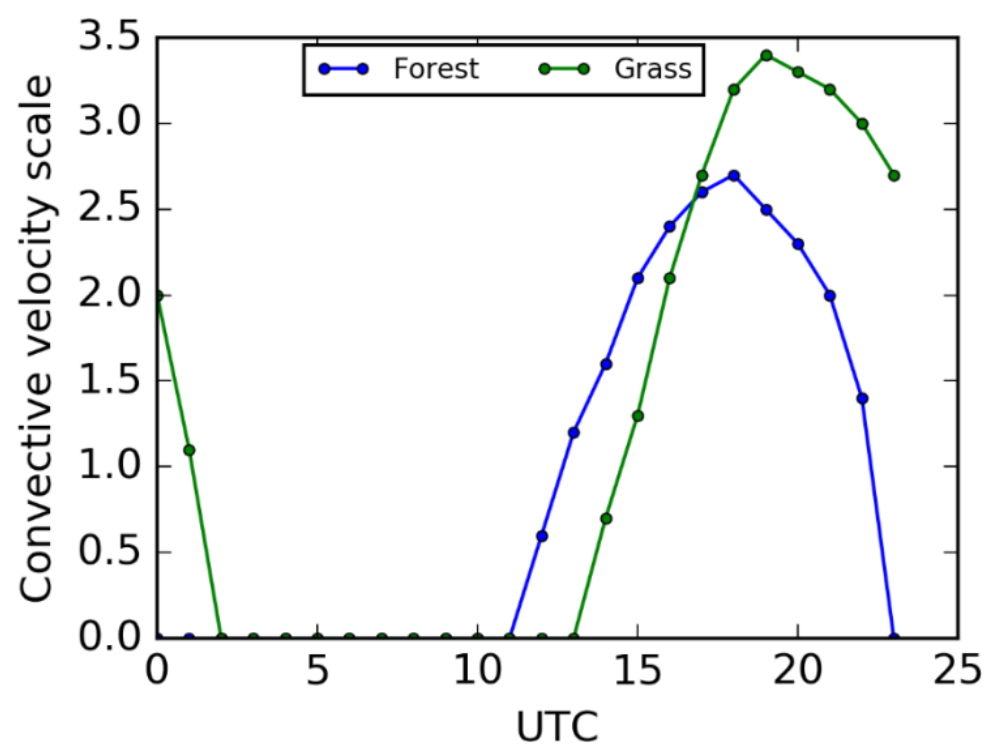

Fig. S2. Diurnal variations of assumed $w_{\star}$ on forest and grass surface. 


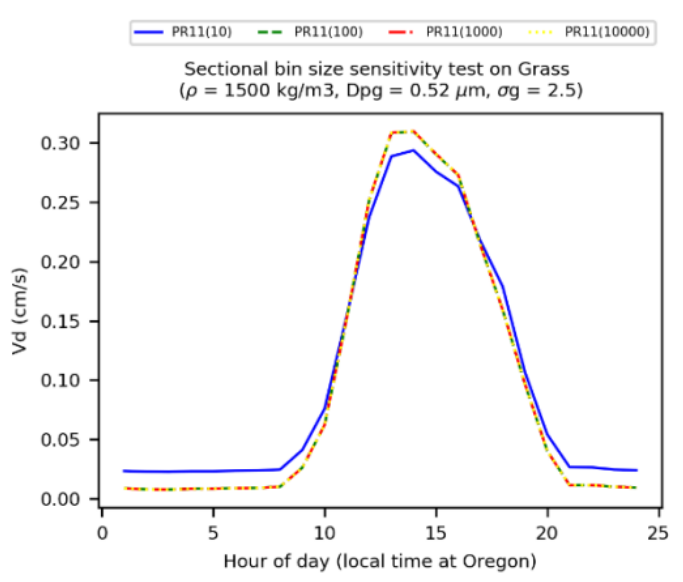

A

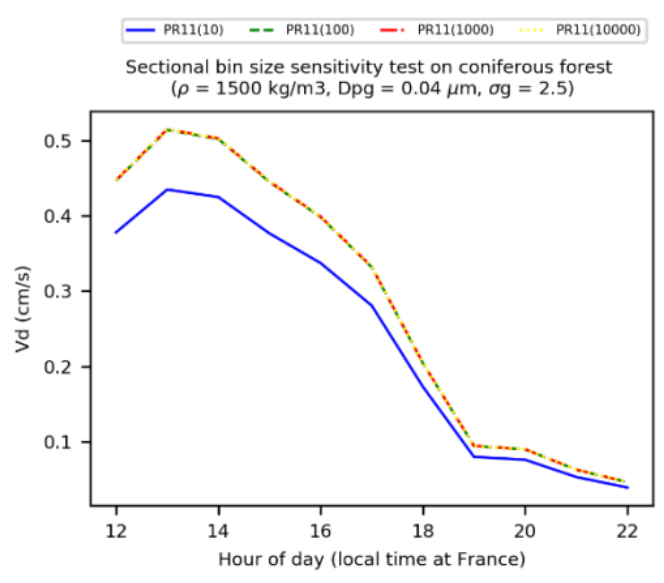

B

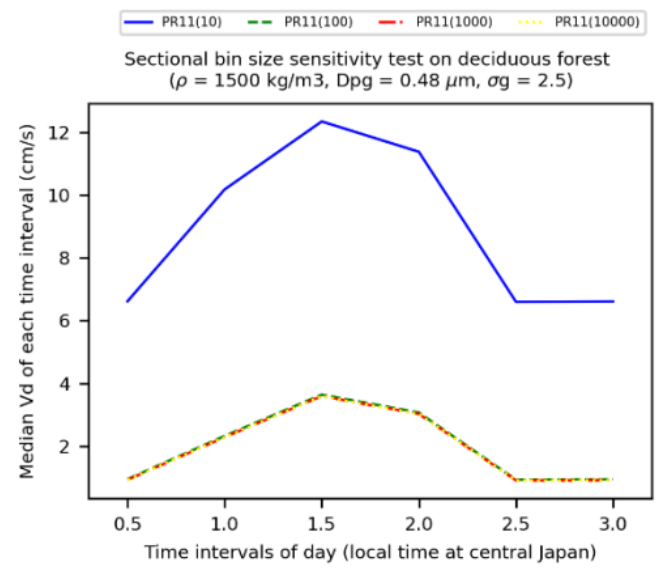

C

Fig. S3. Sensitivity test of bin size in the sectional model, A) Vong et al. (2004) on grass for particle number, B) Lamaud et al. (1994) on the coniferous forest for particle number, C) Matsuda et al. (2010) on the deciduous forest for particle volume. 


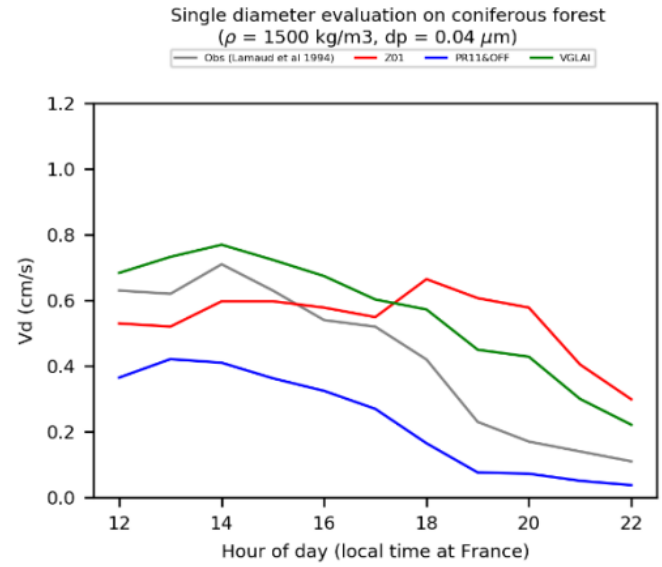

A

B

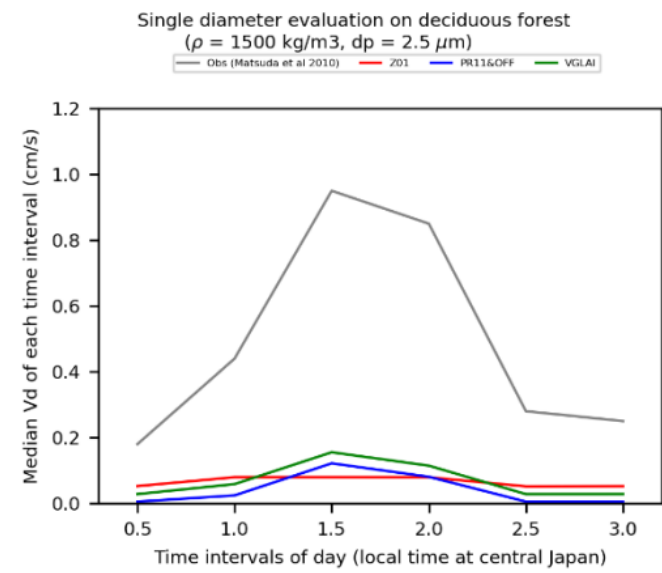

C

Fig. S4. Diurnal variations of dry deposition velocities calculated using single diameter on three different land-use surface categories, $A$ ) instantaneous hourly $V_{d}$ on grass, B) instantaneous hourly $V_{d}$ on coniferous forest, $C$ ) median $V_{d}$ on deciduous forest.

\section{References}

Binkowski, F. S. and Shankar, U.: The Regional Particulate Matter Model: 1. Model description and preliminary results, J. Geophys. Res. Atmospheres, 100, 26191-26209, https://doi.org/10.1029/95JD02093, 1995.

Giorgi, F.: Dry deposition velocities of atmospheric aerosols as inferred by applying a particle dry deposition parameterization

10 to a general circulation model, Tellus B Chem. Phys. Meteorol., 40, 23-41, https://doi.org/10.3402/tellusb.v40i1.15627, 1988. 
Lamaud, E., Brunet, Y., Labatut, A., Lopez, A., Fontan, J., and Druilhet, A.: The Landes experiment: Biosphere-atmosphere exchanges of ozone and aerosol particles above a pine forest, J. Geophys. Res. Atmospheres, 99, 16511-16521, https://doi.org/10.1029/94JD00668, 1994.

5 Matsuda, K., Fujimura, Y., Hayashi, K., Takahashi, A., and Nakaya, K.: Deposition velocity of PM2.5 sulfate in the summer above a deciduous forest in central Japan, Atmos. Environ., 44, 4582-4587, https://doi.org/10.1016/j.atmosenv.2010.08.015, 2010.

Pleim, J. and Ran, L.: Surface Flux Modeling for Air Quality Applications, Atmosphere, 2, 271-302, 10 https://doi.org/10.3390/atmos2030271, 2011.

Peters, K. and Eiden, R.: Modelling the dry deposition velocity of aerosol particles to a spruce forest, Atmospheric Environ. Part Gen. Top., 26, 2555-2564, https://doi.org/10.1016/0960-1686(92)90108-W, 1992.

Slinn, W. G. N.: Precipitation chemistryPredictions for particle deposition to vegetative canopies, Atmospheric Environ. 1967,

15 16, 1785-1794, https://doi.org/10.1016/0004-6981(82)90271-2, 1982.

Vong, R. J., Vickers, D., and Covert, D. S.: Eddy correlation measurements of aerosol deposition to grass, Tellus B, 56, 105117, https://doi.org/10.1111/j.1600-0889.2004.00098.x, 2004.

20 Wiman, B. L. B. and Ågren, G. I.: Aerosol depletion and deposition in forests—A model analysis, Atmospheric Environ. 1967, 19, 335-347, https://doi.org/10.1016/0004-6981(85)90101-5, 1985. 